\title{
O uso do jogo "cartas na mesa" na discussão de fim de vida e alívio de sofrimento
}

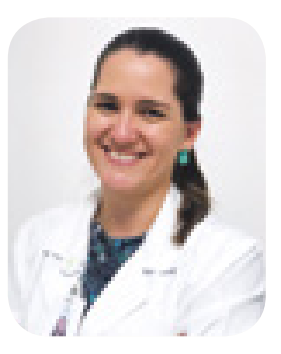

\section{INTRODUÇÃO}

O Cuidado Paliativo é uma abordagem centrada no paciente/família, acometidos por situação clínica que ameaça a vida. Objetiva aprimorar a qualidade de vida destes indivíduos, por meio de ótimo controle de dor e outros sintomas, incorporando os cuidados psicossocial e espiritual, levando em consideração seus valores, crenças e cultura. Esta abordagem busca prevenir e aliviar o sofrimento envolvido no enfrentamento de doenças ameaçadoras da vida e deve ser proposta ao seu diagnóstico. O Cuidado Paliativo assume, contudo, o maior foco do cuidado quando as possibilidades de cura e controle de doença já não são mais possíveis, adequadas ou desejadas. ${ }^{1}$

Nas situações em que as chances de cura ou controle de doença são insignificantes e remotas, a morte é inevitável, são necessários especiais atenção e cuidado com a dignidade humana no tempo que lhe resta. Isso se sobrepõe ao foco de cuidado em simples manutenção da vida, que pode levar ao uso de recursos que apenas lhe prolongam o tempo, às custas de prolongamento de sofrimentos. Deve-se ter em mente que o desenvolvimento tecnológico deve estar a serviço do ser humano, Ihe proporcionando uma vida saudável e digna, e não apenas a extensão de uma vida de sofrimentos e dor. ${ }^{2}$

Em perspectiva, diante de diagnóstico de câncer em face avançada ou terminal, há recomendação que profissionais de saúde proporcionem discussões de plano de cuidados, envolvendo conversas, de preferências, de fim de vida. É sabido que essas discussões não são fáceis, tanto para médicos e demais profissionais de saúde como para pacientes/famílias, carecem de treinamento e disponibilidade da equipe, mas oferecem a oportunidade daqueles expressarem seus desejos e necessidades. Além disso, é o que possibilita o aprimoramento da qualidade de vida, já que esta é individual e deve ser reconhecida através de comunicação sensível e competente por parte dos profissionais. ${ }^{3}$
A despeito disso reconhecido, estudos científicos reconhecem muitas barreiras à comunicação adequada entre equipe e pacientes/famílias, como dificuldades na aceitação de prognóstico, desejo que o tratamento agressivo seja continuado, mesmo diante de perspectivas desfavoráveis, expectativas desproporcionais em relação aos resultados dos tratamentos, dificuldade dos médicos em estabelecer prognósticos precisos e de definir o real benefício dos tratamentos propostos. ${ }^{4}$ Ainda há medo dos profissionais de que essas discussões gerem fragilidade e quebra de confiança na relação médico-paciente. ${ }^{5}$

Em busca de instrumento que facilitasse as conversas sobre o fim da vida, a Coda Alliance criou o "Go Wish Game" (GWG). O jogo inicial, criado para uso de cuidadores leigos, sofreu algumas revisões, assumindo um perfil mais profissional, sendo disseminado e utilizado por profissionais que lidam com pacientes em fases avançadas de doenças ${ }^{6}$, especialmente os profissionais de Cuidados Paliativos. As cartas focam na conversa sobre preferências de fim de vida, em linguagem simples e fácil, dando voz ao paciente, facilitando para eles a expressão das suas vontades.

No Brasil, o GWG foi traduzido e validado para o português pela Sociedade Brasileira de Geriatria e Gerontologia, batizado de "Cartas na Mesa". O jogo é composto de 36 cartas e vem com manual de instruções.

Alguns estudos científicos testaram o impacto do uso do "Cartas na Mesa" como facilitador da discussão sobre o fim de vida, com evidências de que o jogo é de fácil aplicação, necessita de mínimo treinamento para fazê-lo, facilita o início da conversa sobre as preferências de fim de vida e não aumenta a ansiedade dos pacientes/família. ${ }^{3,7}$

\section{EXPOSIÇÃO DO CASO}

A paciente M.M.F., 48 anos, foi avaliada, em primeira consulta, no ambulatório dos Cuidados Paliativos do 
Hospital Santa Izabel, em setembro de 2017. Fora encaminhada pela oncologista assistente, por dor.

Casada, com dois filhos - uma garota de oito anos e um garoto de quatro -, pedagoga e proprietária de uma escola infantil. Contava com o apoio, em especial, do esposo e da amiga Cristina, madrinha de sua filha, para os seus cuidados e na ajuda na condução da rotina da casa e da escola. Era descrita como mulher muito independente, ativa e proativa, que raramente compartilhava seus problemas e angústias, mesmo com os mais próximos.

Recebeu o diagnóstico de câncer um ano antes desta primeira consulta. Fora admitida na emergência por dor abdominal intensa. Após exames e biópsia, teve o diagnóstico de câncer de pâncreas metastático para fígado, incurável. Esta foi uma longa internação, por dificuldade de controle álgico. Necessitou do acompanhamento da Clínica da Dor e de procedimentos invasivos para controle sintomático adequado. Saiu de alta hospitalar com bom controle álgico, mas com perda ponderal e queda do estado geral.

Ambulatorialmente, iniciou o tratamento oncológico paliativo, com quimioterapia. Ao longo de 8 meses de seguimento, melhorou o estado geral, ganhou peso, retomou sua independência, a rotina domiciliar e de trabalho. Voltou a realizar atividades físicas. Após este período, porém, voltou a apresentar dor, quando foi encaminhada aos Cuidados Paliativos.

À primeira avaliação, já usava analgésicos sistemáticos, mas ainda se apresentava com dor forte. Ajustada dose do opioide forte (metadona oral). Retornou em 14 dias, para reavaliação, com bom controle álgico. Reavaliada pela Oncologia Clínica, havia sido definido seguir sem quimioterapia e acompanhamento clínico com exames de imagem.

Em consultas subsequentes, porém, evoluiu com progressiva piora do controle álgico, demanda de aumento progressivo das doses e rotação dos opioides, além de adjuvantes analgésicos. Em dezembro de 2017, foi reinternada pela emergência por piora sintomática. Permaneceu internada, novamente, por tempo prolongado, com demanda de uso de fentanil venoso em infusão contínua e novos procedimentos invasivos para controle de dor. Após período de 38 dias, recebeu alta hospitalar, com dor controlada.

Ao longo desta internação, foi submetida a novos exames de imagem, com evidência de progressão de doença. Comunicada deste resultado, foi discutido com a paciente sobre suas expectativas de evolução e iniciada discussão sobre seus desejos de fim de vida, ainda tímida, pois apresentava grande sofrimento rela- cionado à expectativa de não ver os filhos crescerem. Conversado com o esposo, também, sobre a progressão da doença e expectativa de piora progressiva, a partir dali. O mesmo apresentava boa compreensão do prognóstico, mas com grande sofrimento, por imaginar seguir, em especial, o cuidado dos filhos sem a esposa.

Ambulatorialmente, iniciou a segunda linha de quimioterapia, porém seguiu com piora clínica progressiva, chegando ao PPS 30\%. Voltou em duas consultas com os Cuidados Paliativos, com melhora do controle álgico em relação à internação hospitalar, mas ainda com dor. Proposta internação hospitalar nessas consultas, última em março de 2018, mas a paciente recusou. Em uma delas, referiu preferir estar com dor em casa, pois gostaria de estar presente no aniversário do filho mais novo, que aconteceria em poucos dias. Diante da piora clínica progressiva, foi definido pela oncologista a suspensão definitiva da quimioterapia.

Em abril de 2018, deu entrada na emergência, por dor descontrolada. Nesta oportunidade, apresentava-se emagrecida, lentificada, com anorexia, mas manifestando desejo de não permanecer internada, pois gostaria de estar perto dos filhos. Manifestava importante incômodo por não conseguir mais deambular.

\section{OBJETIVO}

Diante do intenso sofrimento, discutiu-se, em equipe multiprofissional, as possibilidades de abordagem da paciente, nas diferentes dimensões deste sofrimento. Foi proposto o uso do "Cartas na Mesa" para discutir sobre seus desejos de fim de vida. $O$ objetivo seria construir um plano de cuidados que respeitasse seus desejos e crenças, diante da terminalidade.

O instrumento foi aplicado em visita médica junto com a Psicologia, beira-leito, na Unidade de Transição de Pacientes.

\section{MEDIDAS DIAGNÓSTICAS E TERAPÊUTICAS}

O "Cartas na Mesa" é um jogo de cartas usado como recurso para refletir sobre escolhas de fim de vida. As cartas falam acerca de desejar alívio de dor e outros sintomas, estar em paz com Deus, desejo de falar sobre a morte, ter companhias de parentes, amigos e até animais de estimação, contar ou abrir mão de rituais religiosos, morrer em domicílio ou em uma instituição hospitalar, entre outros.

Junto às cartas, há instruções de uso. Contudo, após avaliação da psicóloga ligada à equipe, foi proposta apresentação das cartas em sequência diversa às instruções (tabela 1). Isto deveu-se ao intuito de 
garantir que as cartas fossem apresentadas de forma emocionalmente mais confortável e proporcionando acesso mais profundo ao inconsciente da paciente, respeitando o enunciado de cada uma delas.

As cartas foram aplicadas numa manhã. A paciente encontrava-se lúcida, orientada, entristecida, emagrecida e com aparência desvitalizada, mas com sopro de vida. Queixava-se de dores intensas e sofrimentos nas dimensões de seu corpo, alma e espírito. Falava sobre a dor de deixar de existir, na qual referia dificuldade em pensar e elaborar. Ao discutir as cartas, após ajuste analgésico e melhor conforto, à medida que elas eram apresentadas, a paciente pontuou seu desejo de ser desospitalizada, retornar ao lar para estar mais próxima dos filhos. Contudo, em caso de piora clínica, gostaria de voltar ao hospital, pois não desejava morrer em domicílio. Expressou vontade de não ser reanimada ou submetida a medidas artificiais de manutenção da vida, se fosse mesmo morrer, e de participar das discussões sobre seus cuidados.

A paciente solicitou repousar, antes de esgotadas todas as cartas (apresentadas 15). A despeito disso, no dia subsequente, externou que, após ter conversado mais profundamente acerca de seus desejos de fim de vida, se sentiu aliviada emocionalmente e expressou frase simbólica: "tenho impressão que tirei um grande peso das costas, consegui expressar coisas que estavam guardadas comigo, que agora também estão com vocês, que poderão fazê-las acontecer conforme meu desejo". Ainda neste segundo dia, referiu melhor controle de dor.

Diante da manifestação do desejo de desospitalização, a assistente social organizou conferência familiar, com a participação do esposo e de Cristina. Esse encontro aconteceu com anuência da paciente e sua autorização de que as informações de seus desejos de fim de vida fossem compartilhadas com os familiares. Participaram da conferência a assistente social, a médica e a psicóloga, quando pôde-se acolher e escutar as demandas externadas pelos familiares, bem como oferecer as orientações acerca do plano e continuidade dos cuidados a partir de então, respeitando a vontade da paciente de permanecer o maior tempo possível com seus filhos e na ambiência do lar, junto a suas memórias afetivas. Foi identificado o perfil sócioeconômico, a dinâmica e a organização familiar, que era elegível para os cuidados em domicílio.

Compartilhado com a família o desejo da paciente de não morrer em domicílio e ser reinternada no hospital no processo ativo de morte, pois desejava resguardar as crianças do momento exato da morte.

\section{DISCUSSÃO}

Os avanços tecnológicos da Medicina trouxeram, para além da possibilidade de se viver mais, a capacidade de se impedir de morrer ${ }^{8}$ e prolongar situações de sofrimento irreversível. Dois princípios dos Cuidados Paliativos - reafirmação da vida, sem negação da morte, assumindo-a como processo natural, e o não acelerar, nem adiar a morte - buscam garantir que os pacientes portadores de doenças avançadas, incuráveis, tenham assegurado o respeito à autonomia $\mathrm{e}$ dignidade, proporcionando-lhes a garantia da melhor qualidade possível no fim de vida, evitando-se prolongamento desnecessário de sofrimentos. Comunicação sensível e competente é o caminho para conhecer os desejos de fim de vida do paciente, seus valores e crenças.

Muitos trabalhos trazem evidências de como discussões sobre preferências de fim de vida influenciam positivamente a qualidade de vida dos pacientes em fim de vida, inclusive pacientes oncológicos. Notável estudo de 2010 evidenciou não só melhor qualidade de vida de pacientes oncológicos acompanhados pelos Cuidados Paliativos desde o diagnóstico, mas também maior sobrevida dos mesmos. Análise secundária evidenciou menos uso de quimioterapia nos últimos 60 dias de vida. Os resultados foram atribuídos ao fato dos pacientes terem seus desejos de fim de vida reconhecidos e respeitados até a morte. ${ }^{9}$

Em contrapartida, muitos estudos também evidenciam as muitas barreiras, tanto de pacientes/famílias como de médicos e equipe multiprofissional, para o estabelecimento de discussões adequadas a respeito dos desejos relacionados ao fim de vida. ${ }^{4,5}$

Alguns estudos internacionais já avaliaram a utilidade e o benefício do uso do GWG, com resultados animadores. No Brasil, ainda não existem estudos e as equipes de saúde do país devem encorajar-se a fazê-los, já que as realidades culturais diversas podem ter alguma influência no sucesso do uso do instrumento.

A equipe de Cuidados Paliativos do Hospital Santa Izabel usou o "Cartas na Mesa" para discussão sobre questões de fim de vida com paciente portadora de doença terminal, em sofrimento intenso, de ordens física, psíquica, social e espiritual. O uso do instrumento foi feito com adaptações, realizadas pela psicóloga, levando em consideração o que já era conhecido da equipe sobre o perfil psicológico da paciente. $O$ instrumento mostrou-se um facilitador dessa discussão. Segundo a paciente, apesar de ter se tratado de uma conversa difícil, proporcionou-lhe falar sobre desejos que ela ainda não havia expressado e que considerou 
importante ter revelado. Não é possível garantir elo de ligação direto, mas a paciente apresentou melhora do controle de dor, nas 24 horas subsequentes ao uso do jogo, o que faz refletir se a comunicação adequada e a possibilidade de expressão de seus desejos exerceram influência no controle dos componentes psíquicos e emocionais da dor, aquilo chamado pela Dra. Cicely Saunders de dor total.

Além do exposto, esta abordagem viabilizou planejar seus últimos dias de vida, conforme suas vontades, serenidade aos familiares em respeitá-las e morte no ambiente escolhido pela paciente.

\section{CONCLUSÃO}

O uso do "Cartas na Mesa" apresenta-se como um instrumento promissor em facilitar e viabilizar as discussões sobre fim de vida entre profissionais de saúde e pacientes/famílias. No caso da paciente oncológica, acompanhada pela equipe de Cuidados Paliativos do Hospital Santa Izabel, mostrou-se como um instrumento facilitador desta conversa, possivelmente, influenciou em melhor controle sintomático e viabilizou plano de cuidados em consonância às vontades da paciente.

Contudo, é necessário a realização de mais estudos para confirmar o seu benefício e segurança no auxílio às discussões de fim de vida com paciente/famílias em situações de doenças terminais, oncológicos e não oncológicos.

Tabela 1 - Adaptação da ordem de aplicação das cartas do "Cartas na Mesa"

\begin{tabular}{clc}
\hline $\begin{array}{l}\text { Ordem } \\
\text { apresen- } \\
\text { tada }\end{array}$ & Enunciado das cartas & $\begin{array}{c}\text { Ordem } \\
\text { original }\end{array}$ \\
\hline 1 & $\begin{array}{l}\text { Quero participar do planejamento dos } \\
\text { meus cuidados. }\end{array}$ & 32 \\
\hline 2 & $\begin{array}{l}\text { Quero um médico em que eu confie e } \\
\text { enfermeiros cuidadosos. }\end{array}$ & 4 \\
\hline 3 & $\begin{array}{l}\text { Quero minha família e meus amigos } \\
\text { perto de mim. }\end{array}$ & 19 \\
\hline 4 & $\begin{array}{l}\text { Não quero me sentir pressionado. } \\
\text { Quero ser visto apenas pelas pessoas }\end{array}$ & 10 \\
\hline 6 & $\begin{array}{l}\text { que eu escolher. } \\
\text { Quero saber o que vai acontecer em }\end{array}$ & 5 \\
\hline 7 & Qeguida. & 1 \\
\hline
\end{tabular}

\begin{tabular}{|c|c|c|}
\hline 8 & Quero falar sobre o que fiz na vida. & 13 \\
\hline 9 & $\begin{array}{l}\text { Quero falar sobre meus medos, inclusi- } \\
\text { ve o medo de morrer. }\end{array}$ & 7 \\
\hline 10 & Quero preservar minha dignidade. & 12 \\
\hline 11 & $\begin{array}{l}\text { Quero que minha família respeite mi- } \\
\text { nhas vontades. }\end{array}$ & 16 \\
\hline 12 & $\begin{array}{l}\text { Não quero ser mantido vivo por máqui- } \\
\text { nas, se for mesmo morrer. }\end{array}$ & 3 \\
\hline 13 & $\begin{array}{l}\text { Não quero ser um peso para a minha } \\
\text { família. }\end{array}$ & 21 \\
\hline 14 & Prefiro morrer em casa. & 2 \\
\hline 15 & Não quero morrer sozinho. & 20 \\
\hline 16 & $\begin{array}{l}\text { Quero manter o senso de humor ao } \\
\text { meu redor. }\end{array}$ & 23 \\
\hline 17 & Quero ouvir minhas músicas preferidas. & 6 \\
\hline 18 & $\begin{array}{l}\text { Quero a companhia dos meus animais } \\
\text { de estimação. }\end{array}$ & 15 \\
\hline 19 & Quero ficar apresentável. & 31 \\
\hline 20 & $\begin{array}{l}\text { Quero que minha família traga as comi- } \\
\text { das de que eu gosto. }\end{array}$ & 29 \\
\hline 21 & Quero poder ajudar outras pessoas. & 24 \\
\hline 22 & $\begin{array}{l}\text { Quero conversar sobre doação de } \\
\text { órgãos. }\end{array}$ & 30 \\
\hline 23 & $\begin{array}{l}\text { Quero que minhas finanças estejam } \\
\text { organizadas. }\end{array}$ & 25 \\
\hline 24 & Quero fazer ou revisar meu testamento. & 26 \\
\hline 25 & $\begin{array}{l}\text { Quero conversar sobre minhas necessi- } \\
\text { dades espirituais. }\end{array}$ & 9 \\
\hline 26 & $\begin{array}{l}\text { Gostaria de um objeto religioso perto } \\
\text { de mim. }\end{array}$ & 11 \\
\hline 27 & $\begin{array}{l}\text { Quero fazer uma diretiva antecipada de } \\
\text { vontade. }\end{array}$ & 27 \\
\hline 28 & $\begin{array}{l}\text { Quero ficar limpo, aquecido e confor- } \\
\text { tável. }\end{array}$ & 33 \\
\hline 29 & Quero alívio da dor e da falta de ar. & 35 \\
\hline 30 & $\begin{array}{l}\text { Quero que tudo esteja organizado para } \\
\text { o meu funeral. }\end{array}$ & 28 \\
\hline 31 & $\begin{array}{l}\text { Quero rituais religiosos antes e depois } \\
\text { da minha morte. }\end{array}$ & 14 \\
\hline 32 & $\begin{array}{l}\text { Meus entes queridos podem chorar ou } \\
\text { rir perto de mim. }\end{array}$ & 17 \\
\hline 33 & $\begin{array}{l}\text { Gostaria que minha família aceitasse e } \\
\text { acolhesse a minha morte. }\end{array}$ & 18 \\
\hline 34 & Quero estar alerta quando morrer. & 34 \\
\hline 35 & $\begin{array}{l}\text { Quero poder dizer: Obrigado, Eu te } \\
\text { amo, Me desculpe, Adeus. }\end{array}$ & 22 \\
\hline
\end{tabular}




\section{REFERÊNCIAS}

1. NCCN Clinical Practice Guidelines in Oncology - Palliative Care. Version 1.2018, dezembro, 2017. Disponível em nccn.org.

2. Godinho, MA, et. al., Tratado Brasileiro sobre Direito Fundamental à Morte Digna, Almedina, 2017.

3. Delgado-Guay, MO, et. al., Advanced cancer patients' reported wishes at the end of life: a randomized controlled trial. Support Care Cancer. 24:4273-4281; 2016.

4. Ethier, J-L, et. al., Perceived Barriers to Goals of Care Discussions With Patients With Advanced Cancer and Their Families in the Ambulatory Setting. A Multicenter Survey of Oncologists. Journal of Palliative Care. Abril, 2018.

5. Prod'homme, C., Barriers to end-of-life discussions among hematologists: A qualitative study. Palliative Medicine. Abril, 2018.

6. Menkin, ES., Go Wish: a tool for end-of-life care conversations. J Palliative Med. 10(2):297-303; 2007.

7. Lankarani-Fard, A., et. al., Feasibility of Discussing End-of-Life Care Goals with Inpatients Using a Structured, Conversational Approach: The Go Wish Card Game. Journal of Pain and Symptom Management. 39(4):637-643; 2010.

8. Bobbio, N., O tempo da memória: De senectude e outros escritos autobiográficos. Campus, 1997.

9. Temel, JS., et.al., Early Palliative Care for Patients with Metastatic Non-Small-Cell Lung Cancer. N Engl J Med. 363:733-42; 2010.

1- Serviço de Cuidados Paliativos do HSI

2- Serviço de Psicologia do HSI

3- Serviço Social do HSI

Endereço para correspondência:

manuele.alencar@gmail.com 